\title{
Derecho humano al gentilicio. Caso: Ciudad de México
}

\author{
Human right to demonym. Case: Mexico City
}

\section{Víctor Amaury SIMENTAL FRANCO*}

RESUMEN: Se propone un nuevo integrante al conjunto de los derechos humanos: "el derecho humano al gentilicio"; se justifica la inclusión de este derecho en el conjunto antes indicado con base en la esencia axiológica de los derechos humanos: la dignidad. Por ello, se realiza un estudio casuístico que sustenta la necesidad de reconocer el gentilicio (como derecho humano) a las personas originarias de la Ciudad de México.

Palabras clave: derechos humanos, gentilicio, Ciudad de México.
ABSTRACT: A new member is proposed to the whole of the human rights: "the human right to the demonym"; It is justified the inclusion of this right in the aforementioned set, based on the axiological essence of human rights: dignity. A casuistic study is carried out that supports the need to recognize the demonym (as human right) to people originating in Mexico City.

Keywords: Human rights, demonym, Mexico City.

* Investigador en la Universidad del Valle de México San Ángel, México, Licenciado, maestro y doctor en derecho por la UNAM. Investigador nacional nivel 1; simen tal_franco@yahoo.com.mx. 
SUMARIO: I. Marco teórico conceptual. II. Necesidad del reconocimiento al derecho humano al gentilicio. III. Caso paradigmático: Ciudad de México. IV. Conclusiones. V. Bibliografía.

\section{MARCO TEÓRICO CONCEPTUAL}

\section{Derechos humanos}

Los derechos humanos son un concepto jurídico caracterizado por manifestar las mínimas condiciones que permiten la realización plena de las personas. La Oficina del Alto Comisionado para los Derechos Humanos de las Naciones Unidas los define del modo siguiente:

Los derechos humanos son derechos inherentes a todos los seres humanos, sin distinción alguna de nacionalidad, lugar de residencia, sexo, origen nacional o étnico, color, religión, lengua, o cualquier otra condición. Todos tenemos los mismos derechos humanos, sin discriminación alguna. Estos derechos son interrelacionados, interdependientes e indivisibles. ${ }^{1}$

La nota más característica de los derechos humanos, como un conjunto distintivo dentro del inconmensurable catálogo de los derechos subjetivos, es el relativo a la dignidad. ${ }^{2}$

Junto con el desarrollo de los derechos humanos va el de la dignidad, pues es precisamente en relación con la tutela, protección y promoción de la dignidad humana en los ámbitos jurídico y político que los derechos humanos tienen sentido y alcanzan una dimensión moral, por eso el desarrollo doctrinal de la teoría de los derechos humanos atribuyéndoles como fundamento y razón de su existencia precisamente a la dignidad de la persona o a alguno de sus atributos. ${ }^{3}$

\footnotetext{
1 Disponible en: http://www.ohchr.org/SP/Issues/Pages/WhatareHumanRights.aspx.

2 Cfr. Carpizo, Jorge, "Los derechos humanos: naturaleza, denominación y características", Cuestiones Constitucionales, Revista Mexicana de Derecho Constitucional, núm. 25, julio-diciembre de 2011.

3 Martínez Bullé-Goyri, Víctor M., "Reflexiones sobre la dignidad humana en la actualidad", Boletín Mexicano de Derecho Comparado, nueva serie, año XLVI, núm. 136, enero-abril de 2013, pp. 39-67.
} 
Hoy entendemos a los derechos humanos no sólo como la expresión ética más acabada del derecho, sino como la expresión jurídica de la dignidad humana. Esto es, los derechos humanos, originalmente concebidos como instrumento para defender al individuo de las acciones de la autoridad que pudieran afectar o agredir a su dignidad, hoy día en las sociedades contemporáneas tienen el carácter de paradigma ético y regla moral. ${ }^{4}$

Los derechos humanos no solamente deben ser vistos en cuanto a su perspectiva activa, sino también en cuanto al papel "pasivo" de los Estados, que están obligados a garantizarlos.

Los derechos humanos incluyen tanto derechos como obligaciones. Los Estados asumen las obligaciones y los deberes, en virtud del derecho internacional, de respetar, proteger y realizar los derechos humanos. La obligación de respetarlos significa que los Estados deben abstenerse de interferir en el disfrute de los derechos humanos, o de limitarlos. La obligación de protegerlos exige que los Estados impidan los abusos de los derechos humanos contra individuos y grupos. La obligación de realizarlos significa que los Estados deben adoptar medidas positivas para facilitar el disfrute de los derechos humanos básicos. En el plano individual, así como debemos hacer respetar nuestros derechos humanos, también debemos respetar los derechos humanos de los demás. ${ }^{5}$

Se ha discutido mucho en torno a la naturaleza de los derechos humanos, pudiendo resumirse en dos grandes ópticas: en una se afirma que los derechos humanos son los que el Estado concede. La otra posición indica que el Estado únicamente reconoce los derechos. Es evidente que la primera postura corresponde al pensamiento ius positivista, mientras que la otra perspectiva está relacionada con el derecho natural. Carpizo, al respecto, indica:

En conceptos jurídicos, en el positivismo se expresa que es el orden jurídico el que otorga la calidad de persona al ser humano; es decir, persona es una categoría jurídica que se puede conceder o no, o de la cual se puede excluir a un ser humano o a un grupo de ellos, como pueden ser los esclavos, los extranjeros, las mujeres, por razones de raza o por preferencias sexuales. En cambio, en las concepciones de derecho natural el ser humano, por el solo hecho de existir, es persona y posee derechos y obligaciones; o sea, el Estado no puede desconocer esta situación, lo único que realiza

4 Idem.

5 Disponible en: http://www.ohchr.org/SP/Issues/Pages/WhatareHumanRights.aspx. 
es el reconocimiento de este hecho, y a partir de él se garantizan diversas series de derechos, a los cuales en la actualidad se les denomina derechos humanos. ${ }^{6}$

Las concepciones de derecho natural coinciden entonces en este tronco común de pensamiento y a partir de él toman derroteros muy diversos. Por ejemplo, algunos escritores piensan que la persona tiene una dignidad intrínseca por el hecho de estar en relación directa con lo absoluto. Otros, entre los que me incluyo, consideramos que no es correcto plantear el problema en esta forma, sino que la base de los derechos humanos se encuentra en la dignidad de la persona, y nadie puede legítimamente impedir a otro el goce de esos derechos. El hombre sólo puede realizarse dentro de la comunidad social, y esta comunidad no tiene otro fin que servir a la persona. El fin de la comunidad es la realización de una obra en común, y ésta consiste en que cada hombre viva como persona; es decir, con dignidad humana. ${ }^{7}$

Puede afirmarse, con base en la evidencia empírica, que los derechos humanos, en su concepción moderna y contemporánea, han significado la inclusión dentro del derecho positivo de elementos que originalmente estaban destinados al derecho natural, pero que, ante el surgimiento de los regímenes totalitarios, tanto de derecha como de izquierda, que podían justificar realizar actos totalmente contra la humanidad con base en que el orden jurídico del Estado los contemplaba, mostraron la necesidad de "positivar" al derecho natural.

\section{A. Situación constitucional de los derechos humanos en el Estado mexicano}

Aunque en México se puede afirmar que desde sus orígenes constitucionales (Constitución de Apatzingán) se encuentra el reconocimiento pleno a ciertos derechos humanos y que además a nuestro país le corresponde el honor de haber sido origen de la segunda generación de derechos humanos, con la promulgación de la Constitución de 1917, la realidad es que la implementación de los derechos humanos de manera plena en el entramado constitucional del Estado mexicano ha pasado por un largo recorrido que puede afirmarse culminó con la reforma constitucional

\footnotetext{
6 Carpizo, Jorge, op. cit.

7 Idem.
} 
de junio de 2011, pero que aun debe pasar por la implementación en la legislación secundaria y, sobre todo, la aplicación efectiva y eficiente de los operadores jurídicos.

Es ampliamente reconocido que la integración al orden jurídico nacional de los derechos humanos se dio a través de la influencia directa e indirecta del derecho internacional, ya sea mediante la asignación de tratados internacionales por el Estado mexicano y también por el impacto que han tenido en la doctrina nacional los trabajos desarrollados por teóricos de otras latitudes (especialmente Europa).

Ahora bien, siguiendo el modelo nórdico, en los años ochenta del siglo pasado se consideró necesario dotar de una estructura formal que tutelara a los derechos humanos, de tal manera que se dio inicio a su institucionalización, misma que se describe sucintamente en los párrafos siguientes.

Respecto de los antecedentes directos de la CNDH, el 13 de febrero de 1989, dentro de la Secretaría de Gobernación, se creó la Dirección General de Derechos Humanos. Un año más tarde, el 6 de junio de 1990 nació por decreto presidencial una institución denominada Comisión Nacional de Derechos Humanos, constituyéndose como un Organismo desconcentrado de dicha Secretaría. Posteriormente, mediante una reforma publicada en el Diario Oficial de la Federación el 28 de enero de 1992, se adicionó el apartado B del artículo 102, elevando a la CNDH a rango constitucional y bajo la naturaleza jurídica de un Organismo descentralizado, con personalidad jurídica y patrimonio propios, dándose de esta forma el surgimiento del llamado Sistema Nacional No Jurisdiccional de Protección de los Derechos Humanos. ${ }^{8}$

Finalmente, por medio de una reforma constitucional, publicada en el Diario Oficial de la Federación el 13 de septiembre de 1999, dicho Organismo Nacional se constituyó como una Institución con plena autonomía de gestión y presupuestaria, modificándose la denominación de Comisión Nacional de Derechos Humanos por la de Comisión Nacional de los Derechos Humanos. Esta reforma constituye un gran avance en la función del Ombudsman en México, ya que le permite cumplir con su función de proteger y defender los Derechos Humanos de todos los mexicanos. ${ }^{9}$

En junio de 2011 (6 y 10) se realizaron sendas reformas constitucionales de alto impacto en lo tocante a los derechos humanos, ya que se les dio pleno

8 Disponible en: http://www.cndh.org.mx/Antecedentes.

9 Idem. 
reconocimiento y se integraron al entramado de la estructura constitucional del Estado mexicano.

La Suprema Corte de Justicia de la Nación resume las dos reformas a la Constitución Política de los Estados Unidos Mexicanos en materia de derechos humanos, antes aludidas, que vienen a reforzar la implementación de este constructo jurídico en el orden jurídico nacional:

El 6 y 10 de junio de 2011, se publicaron dos importantes reformas a la Constitución Política de los Estados Unidos Mexicanos que impactan directamente en la administración de justicia federal. ${ }^{10}$

La primera de ellas concierne fundamentalmente al juicio de amparo, institución protectora de los derechos fundamentales por excelencia, el cual se ve robustecido al ampliarse la procedencia del amparo respecto de cualquier norma general, al preverse su procedencia por violaciones a los derechos humanos plasmados en los tratados internacionales de los que el Estado mexicano sea parte; con la introducción de figuras como el amparo adhesivo y los intereses legítimos individual y colectivo; la adopción de nuevos conceptos en torno a la violación de derechos por omisión de las autoridades; la declaratoria general de inconstitucionalidad cuyos alcances y condiciones se determinarán en la ley reglamentaria; la creación de los Plenos de Circuito; y una nueva forma de integrar jurisprudencia "por sustitución"; entre otras. ${ }^{11}$

La segunda, en íntima relación con la anterior, evidencia el reconocimiento de la progresividad de los derechos humanos, mediante la expresión clara del principio pro persona como rector de la interpretación y aplicación de las normas jurídicas, en aquellas que favorezcan y brinden mayor protección a las personas. Así, la ampliación de los derechos que significa la concreción de algunas cláusulas constitucionales, como aquella relativa a los migrantes o a la suspensión de garantías, aunada a la obligación expresa de observar los tratados internacionales firmados por el Estado mexicano, miran hacia la justiciabilidad y eficacia de los derechos que, a la postre, tiende al mejoramiento de las condiciones de vida de la sociedad y al desarrollo de cada persona en lo individual. ${ }^{12}$

El artículo 1o. de la Constitución Política de los Estados Unidos Mexicanos (después de las reformas de junio de 2011) quedó del modo siguiente:

\footnotetext{
10 Disponible en: http://www2.scjn.gob.mx/red/constitucion/inicio.html.

11 Idem.

12 Idem
} 


\section{Título Primero}

Capítulo I

De los Derechos Humanos y sus Garantías

Denominación del Capítulo reformada DOF 10-06-2011

Artículo 1o. En los Estados Unidos Mexicanos todas las personas gozarán de los derechos humanos reconocidos en esta Constitución y en los tratados internacionales de los que el Estado Mexicano sea parte, así como de las garantías para su protección, cuyo ejercicio no podrá restringirse ni suspenderse, salvo en los casos y bajo las condiciones que esta Constitución establece.

Párrafo reformado DOF 10-06-2011

Las normas relativas a los derechos humanos se interpretarán de conformidad con esta Constitución y con los tratados internacionales de la materia favoreciendo en todo tiempo a las personas la protección más amplia.

Párrafo adicionado DOF 10-06-2011

Todas las autoridades, en el ámbito de sus competencias, tienen la obligación de promover, respetar, proteger y garantizar los derechos humanos de conformidad con los principios de universalidad, interdependencia, indivisibilidad y progresividad. En consecuencia, el Estado deberá prevenir, investigar, sancionar y reparar las violaciones a los derechos humanos, en los términos que establezca la ley.

Párrafo adicionado DOF 10-06-2011

Está prohibida la esclavitud en los Estados Unidos Mexicanos. Los esclavos del extranjero que entren al territorio nacional alcanzarán, por este solo hecho, su libertad y la protección de las leyes.

Queda prohibida toda discriminación motivada por origen étnico o nacional, el género, la edad, las discapacidades, la condición social, las condiciones de salud, la religión, las opiniones, las preferencias sexuales, el estado civil o cualquier otra que atente contra la dignidad humana y tenga por objeto anular o menoscabar los derechos y libertades de las personas.

Párrafo reformado DOF 04-12-2006, 10-06-2011 Artículo reformado DOF 14-08-2001

\section{B. Impacto jurisprudencial de la reforma constitucional} de junio de 2011

Los cambios implementados en la Constitución Política de los Estados Unidos Mexicanos en la citada reforma de 2011 significan una modifica- 
ción sustancial al entramado constitucional mexicano, porque implican la implantación de los derechos humanos como eje tutelar del orden jurídico mexicano; se determina un sistema de interpretación de la normatividad que premia a los derechos humanos, ya sea que estén considerados en la propia Constitución o en tratados internacionales: interpretación conforme y pro homine, impone los correlativos deberes del Estado ante los derechos humanos y prohíbe cualquier tipo de discriminación que atente contra la dignidad humana.

Por supuesto que todos estos cambios tuvieron un impacto trascendente en la impartición de justicia, lo cual se vio reflejado en la jurisprudencia emitida por el Poder Judicial, de tal modo que en la búsqueda del constructo derechos humanos en la plataforma electrónica del Semanario Judicial de la Federación, en el periodo de 2011 a 2017 (último año de la Novena Época y lo que va de la Décima Época), arroja 344 tesis y jurisprudencias que en el rubro contienen la expresión indicada, lo que es palpable del notorio impacto que tuvo la reforma de 2011.

Son de destacarse las siguientes jurisprudencias para los fines de este estudio, y es de resaltarse que en ninguna jurisprudencia ni tesis aislada se encuentra alguna definición que acote el concepto de derechos humanos:

Época: Décima Época, Registro: 2008935, Instancia: Primera Sala, Tipo de Tesis: Jurisprudencia, Fuente: Gaceta del Semanario Judicial de la Federación, Libro 17, Abril de 2015, Tomo I, Materia(s): Constitucional, Tesis: 1a./J. 29/2015 (10a.), Página: 240.

DERECHOS HUMANOS RECONOCIDOS TANTO POR LA CONSTITUCIÓN POLítICA DE LOS ESTADOS UNIDOS MEXICANOS, COMO EN LOS TRATADOS INTERNACIONALES. PARA DETERMINAR SU CONTENIDO Y ALCANCE DEBE ACUDIRSE A AMBAS FUENTES, FAVORECIENDO A LAS PERSONAS LA PROTECCIÓN MÁs AMPLIA. Acorde con lo sostenido por el Tribunal en Pleno de la Suprema Corte de Justicia de la Nación, en la tesis de jurisprudencia P./J. 20/2014 (10a.), * las normas de derechos humanos contenidas en los tratados internacionales y en la Constitución Política de los Estados Unidos Mexicanos no se relacionan entre sí en términos jerárquicos, ya que se integran al catálogo de derechos que funciona como un parámetro de regularidad constitucional. Por tanto, cuando un derecho humano esté reconocido tanto en la Constitución Federal, como en los tratados internacionales, debe acudirse a ambas fuentes para determinar su contenido y alcance, favoreciendo en todo tiempo a las personas la protección más amplia; en el entendido de que cuando exista en la Constitución una res- 
tricción expresa al ejercicio de un derecho humano, se deberá estar a lo que indica la norma constitucional.

Época: Décima Época, Registro: 2007981, Instancia: Primera Sala, Tipo de Tesis: Aislada, Fuente: Gaceta del Semanario Judicial de la Federación, Libro 12, Noviembre de 2014, Tomo I, Materia(s): Constitucional, Tesis: 1a. CDV/2014 (10a.), Página: 714.

DERECHOS HUMANOS. SU CONTENIDO NO SE LIMITA AL TEXTO EXPRESO DE LA NORMA QUE LO PREVÉ, SINO QUE SE EXTIENDE A LA INTERPRETACIÓN QUE LOS ÓRGANOS AUTORIZADOS HAGAN AL RESPECTO. La interpretación del contenido de los derechos humanos debe ir a la par de la evolución de los tiempos y las condiciones actuales de vida, pues los textos que reconocen dichos derechos son "instrumentos permanentes" a decir de esta Suprema Corte de Justicia, o "instrumentos vivos" de acuerdo con la jurisprudencia interamericana. Dicho de otra manera, el contenido de los derechos humanos no se limita al texto expreso de la norma donde se reconoce dicho derecho, sino que se va robusteciendo con la interpretación evolutiva o progresiva que hagan tanto los tribunales constitucionales nacionales, como intérpretes últimos de sus normas fundamentales, así como con la interpretación que hagan los organismos internacionales, intérpretes autorizados en relación con tratados específicos, en una relación dialéctica.

Época: Décima Época, Registro: 2003350, Instancia: Tribunales Colegiados de Circuito, Tipo de Tesis: Aislada, Fuente: Semanario Judicial de la Federación y su Gaceta, Libro XIX, Abril de 2013, Tomo 3, Materia(s): Constitucional, Tesis: I.4o.A.9 K (10a.), Página: 2254.

PRINCIPIOS DE UNIVERSALIDAD, INTERDEPENDENCIA, INDIVISIBILIDAD Y PROGRESIVIDAD DE LOS DERECHOS HUMANOS. EN QUÉ CONSISTEN. El tercer párrafo del artículo 1o. de la Constitución Política de los Estados Unidos Mexicanos dispone, entre otras cuestiones, que todas las autoridades, en el ámbito de sus competencias, tienen la obligación de promover, respetar, proteger y garantizar los derechos humanos de conformidad con los principios de universalidad, interdependencia, indivisibilidad y progresividad, los que consisten en lo siguiente: i) universalidad: que son inherentes a todos y conciernen a la comunidad internacional en su totalidad; en esta medida, son inviolables, lo que no quiere decir que sean absolutos, sino que son protegidos porque no puede infringirse la dignidad humana, pues lo razonable es pensar que se adecuan a las circunstancias; por ello, en razón de esta flexibilidad es que son universales, ya que su naturaleza permite que, al amoldarse a las contingencias, siempre estén con la persona. En relación con lo anterior, la Corte Interamericana de Derechos Humanos (Caso de la "Masacre de Mapiripán vs Colombia) 
ha señalado que los tratados de derechos humanos son instrumentos vivos, cuya interpretación tiene que acompañar la evolución de los tiempos y las condiciones de vida actuales, interpretación evolutiva que es consecuente con las reglas generales de interpretación consagradas en el artículo 29 de la Convención Americana sobre Derechos Humanos, así como las establecidas por la Convención de Viena sobre el Derecho de los Tratados. De ahí que dichos derechos, dentro de sus límites, son inalterables, es decir, que su núcleo esencial es intangible; por ello, la Norma Fundamental señala que ni aun en los estados de excepción se "suspenden", pues en todo caso, siempre se estará de conformidad con los principios del derecho internacional humanitario; ii) interdependencia e indivisibilidad: que están relacionados entre sí, esto es, no puede hacerse ninguna separación ni pensar que unos son más importantes que otros, deben interpretarse y tomarse en su conjunto y no como elementos aislados. Todos los derechos humanos y las libertades fundamentales son indivisibles e interdependientes; debe darse igual atención y urgente consideración a la aplicación, promoción y protección de los derechos civiles, políticos, económicos, sociales y culturales; esto es, complementarse, potenciarse o reforzarse recíprocamente; y iii) progresividad: constituye el compromiso de los Estados para adoptar providencias, tanto a nivel interno como mediante la cooperación internacional, especialmente económica y técnica, para lograr progresivamente la plena efectividad de los derechos que se derivan de las normas económicas, sociales y sobre educación, ciencia y cultura, principio que no puede entenderse en el sentido de que los gobiernos no tengan la obligación inmediata de empeñarse por lograr la realización íntegra de tales derechos, sino en la posibilidad de ir avanzando gradual y constantemente hacia su más completa realización, en función de sus recursos materiales; así, este principio exige que a medida que mejora el nivel de desarrollo de un Estado, mejore el nivel de compromiso de garantizar los derechos económicos, sociales y culturales.

Cuarto Tribunal Colegiado en Materia Administrativa del PRIMER CIRCUITO.

\section{Gentilicio}

El diccionario de la Real Academia Española define al gentilicio como:

Del lat. gentilicius, der. de gentìlis «que pertenece a una misma nación o a un mismo linajè.

1. adj. Dicho de un adjetivo o de un sustantivo: Que denota relación con un lugar geográfico. U. t. c. s. m. 
2. adj. Perteneciente o relativo a las gentes o naciones.

3. adj. Perteneciente o relativo al linaje o familia.

Los gentilicios son los nombres y adjetivos que indican de dónde son las personas. Morera refiere que los gentilicios designan de forma mostrativa o identificadora, mediante un adjetivo de relación derivado del nombre propio del lugar en que nacieron. ${ }^{13}$ Se utilizan para designar a las personas o gentes de un país, región o ciudad. Por extensión, se aplican también a animales, plantas y cosas. ${ }^{14}$

Sea adjetivo o sustantivo, el gentilicio denota el origen de las personas o de las cosas, no su residencia o ubicación. Una persona conservará su gentilicio no importa dónde viva; digamos que es un signo más de identificación de la persona; podríamos atrevernos a decir que, aun cuando no está legislado al respecto, incluye junto al nombre, patrimonio, domicilio, nacionalidad y estado civil, un atributo de la personalidad.

El gentilicio actúa, pues, como una especie de archivo que contiene todos los datos de la gente, los animales, las plantas, los fenómenos naturales, etc., del lugar a que se refiere, y de todas las cosas pertenecientes o relativas a ellos, reales o atribuidas, insistimos. ${ }^{15}$

Hasta tal punto es así, que se puede decir que el gentilicio es la palabra que mejor define al hombre como miembro de una colectividad. Es lo que explica la sensación de carencia o manquedad que se siente cuando un determinado pueblo, por las razones que sean, no ha actualizado el gentilicio que le corresponde. ${ }^{16}$

Como ya se indicó, gentilicio deriva del latín gentilitius, un vocablo que a su vez proviene de gens, que significa familia o tribu. En general, el nombre de la localidad de nacimiento es lo que determina normalmente el gentilicio.

Sin embargo, no siempre hay una correlación entre la toponimia y el gentilicio, tal y como sucede con los casos siguientes: en España, los del

13 Morera, Marcial, “Gentilicios y seudogentilicios: mostración vs. descripción”, Revista de Lexicografía, XVIII, 2012, p. 103.

14 Cuervo Álvarez, Benedicto, Textos literarios. Gramática, sintaxis y ortografía (1/3), disponible en: http://www.mailxmail.com/curso-textos-literarios-gramatica-sinta xis-ortografia-1-3/gramatica-gentilicios.

15 Morera, Marcial, op. cit., p. 111.

16 Idem. 
pueblo de Andújar son iliturgitanos, los de Almuñécar son sexitanos, los de Huelva son onubenses; en Colombia, a los de Medellín y los del departamento de Antioquía se les conoce como paisas. ${ }^{17}$

Aunque si bien se carece de una regla explícita para la creación de los gentilicios, lo más común es que el nombre del lugar de nacimiento (su topónimo) determina el nombre que se les da a sus habitantes.

El uso de los gentilicios cambia según el contexto de la comunicación. La procedencia geográfica de las personas es el factor determinante para la formación de un gentilicio, de tal forma que las personas pueden ser agrupadas por continentes, países, regiones, ciudades e incluso por barrios. ${ }^{18}$

Casos raros y otros que generan cierta confusión. Hay gentilicios totalmente obvios, como caboverdiano, asturiano, gallego o italiano. En cambio, algunos son bastante curiosos y raros, como malgache para referirse a los habitantes de Madagascar y ceilandés para los que son de Sri Lanka. En ocasiones se pueden dar confusiones derivadas de la similitud entre el nombre de dos países (austriaco es el gentilicio de Austria y australiano de Australia). ${ }^{19}$

José Guadalupe Moreno de Alba, posiblemente la máxima autoridad filológica de México durante el siglo XX y parte del XXI, opina en sentido contrario, y considera que sí existen reglas gramaticales para fijar un gentilicio, lo que exponía del modo siguiente:

La gramática explica que el adjetivo gentilicio es aquel que denota la procedencia geográfica de las personas o su nacionalidad. Los gentilicios pertenecen a la clase de palabras llamadas "derivadas". Constan éstas de una raíz y de un sufijo (mexicano: mexic- [raíz] + -ano [sufijo]). En el caso de los gentilicios, en la raíz está la información del lugar; el concepto 'originario, procedente de' está en el sufijo (mexicano: 'originario, procedente de México'). Los gentilicios, como cualquier otro tipo de palabras derivadas, se estudian en la morfología (una de las partes de la gramática). No toda palabra que designa procedencia u origen es un gentilicio. Para que un adjetivo pueda llamarse gentilicio se requiere que esté formado precisamente mediante una derivación: mexicano procede de México; madrileño, de Madrid; aguascalentense,

17 Cfr. https://www.definicionabc.com/geografia/gentilicio.php.

18 Idem.

19 Idem. 
de Aguascalientes... Hay en español muchas palabras que, sin ser derivadas, designan procedencia u origen. No conviene llamarlas gentilicios, pues al no ser derivadas, no constan de raíz y sufijo, como se exige que estén formados los gentilicios. ${ }^{20}$

Es importante traer a colación la importante distinción que hace Alemán Ocampo entre gentilicio y apodo colectivo, ${ }^{21}$ quien al respecto indica lo siguiente:

Como principio metodológico, establezcamos que los apodos colectivos no se han incluido, como categoría denominativa, en las clasificaciones de los nombres, propios o comunes, ni en las formas adjetivas en la gramática española. $^{22}$

Los gentilicios son palabras derivadas en las que participan la raíz con el nombre del lugar y el componente morfológico, de diferente composición, que indica pertenencia a un lugar. Los estudios morfológicos establecen una cantidad respetable de morfemas utilizados en lengua española, muchos de los cuales son de uso corriente en Nicaragua. Incluido el -ense de origen directamente latino, usado para nuestro gentilicio nacional: nicaragüense. ${ }^{23}$

Cuando me refiero a la existencia o no de un gentilicio, me refiero al uso que le da corrientemente la gente y no a las pretensiones de profesores de gramática que, con afán normativo, inventan gentilicios donde no los hay. ${ }^{24}$

Los apodos, nos dice Alemán Ocampo, "de acuerdo con la Gramática Descriptiva son nombres que indican una nota particular en un individuo, nosotros agregamos, además grupo de individuos, que puede ser más o menos numeroso, por ejemplo: tan grande como yanki o gringo para referirnos a los norteamericanos o estadounidenses". 25

20 Moreno de Alba, José Guadalupe, Minucias del lenguaje, México, Fondo de Cultura Económica, disponible en: https://www.fondodeculturaeconomica.com/obra/suma/r2/ buscar.asp? word $2=$ chilango .

21 Morero alude a este concepto bajo la denominación de "seudogentilicio"; $c f r$., Morera, Marcial, op. cit., p. 121.

22 Alemán Ocampo, Carlos, No confundamos apodos colectivos con gentilicios, disponible en: http://www.elcastellano.org/artic/gentilicios.htm.

23 Idem.

24 Idem.

25 Alemán Ocampo, Carlos, op. cit. 
Los apodos pueden ser cariñosos, ofensivos, despectivos, pero siempre se originan a partir de rasgos particulares. En algunos casos se los cargan los vecinos del otro lado de la frontera y en otros se los cargan los mismos que los llevan. Y que no tiene el aspecto morfológico requerido para que gramaticalmente conformen las reglas establecidas para que se integre un gentilicio. ${ }^{26}$

A estos apodos, dichos con la intencionalidad de señalar defectos o virtudes, que no son verdaderos gentilicios, se les debe llamar simplemente como "apodos colectivos".

Algunos ejemplos de apodos colectivos son:

- Para los guatemaltecos, chapín.

- A los salvadoreños se les llama cuzcatlecos.

- Para los hondureños se usa el de catrachos.

- A los nicaragüenses se les llama simplemente nicas.

- Para los costarricenses existe el tico.

- A los nacidos en la Ciudad de México, chilangos.

\section{Nacionalidad y gentilicio}

La nacionalidad es generalmente definida ya sea como el vínculo jurídico y político existente entre un Estado y los miembros del mismo, o como el estatus civil de la persona que le vincula a un Estado, ya sea por causa de nacimiento, por lazos de sangre paterna o materna, o por un proceso jurídico-político de naturalización.

Batiffol la define como "la pertenencia jurídica de una persona a la población constitutiva de una Estado".27

Hauriou indica que "la nacionalidad implica, ante todo una «mentalidad» creada por la confluencia de uno o varios factores (historia, raza, legua, religión, condicionamientos geográficos u otros)". ${ }^{28}$

Para Niboyet, "la nacionalidad es el vínculo político y jurídico que relaciona a un individuo con un Estado. La nacionalidad ha de considerarse

\footnotetext{
26 Idem.

27 Citado por Pereznieto, Leonel, Derecho internacional privado, México, Harla, 1994, p. 33.

28 Citado por Pérez, Elisa, Derecho internacional privado, Madrid, Facultad de Derecho de la Universidad Nacional de Educación a Distancia, 1990, t. I, p. 157.
} 
siempre desde el punto de vista puramente político, de la conexión de los individuos con un Estado determinado. ${ }^{29}$

La Corte Internacional de Justicia se refiere a la nacionalidad como "un vínculo jurídico basado en un hecho social de conexión, en una efectividad solidaria de existencia de intereses y sentimientos, unido a una reciprocidad de derechos y deberes". ${ }^{30}$ Arlettaz indica, atinadamente, que "la nacionalidad sigue siendo uno de los elementos fundamentales para la definición del Estado. Si el territorio determina los límites geográficos de la soberanía estatal, la nacionalidad determina sus límites humanos. Más allá de estos límites hay territorio extranjero, soberanía extranjera y extranjeros". ${ }^{31}$

Las similitudes entre nacionalidad y gentilicio son notorias, pues ambos conceptos relacionan a los individuos con su origen nacional (aunque el gentilicio puede ser, de hecho es, mucho más restrictivo, vinculando al sujeto con una ciudad); en ambos casos, el reconocimiento jurídico puede ser hasta secundario, pues para el individuo es más trascendente su vinculación emotiva, su sentido de pertenencia. La nacionalidad, por otro lado, es un concepto de impacto internacional, referente necesario para viajar de un Estado a otro; el gentilicio en este supuesto es secundario, aunque no sé de ningún caso en el que haya nacionalidad sin gentilicio.

En tanto que la nacionalidad es motivo de una amplia tutela jurídica, tanto al interior de los Estados como en las relaciones internacionales, el gentilicio no había sido considerado, ni por la teoría, mucho menos por la legislación.

\section{NECESIDAD DEL RECONOCIMIENTO AL DERECHO HUMANO} AL GENTILICIO

La Convención Americana sobre Derechos Humanos indica, en su artículo 20, lo siguiente:

29 Niboyet, J. P., Principios de derecho internacional privado, México, Ed. Nacional, 1965, p. 77.

30 Corte Internacional de Justicia (CIJ), Affaire Nottebohm (Liechtenstein v. Guatemala), Deuxième phase: arrêt, Recueil, 1955, p. 23, citado por Arlettaz, Fernando, "La nacionalidad en el derecho internacional americano", Anuario Mexicano de Derecho Internacional, vol. XV, 2015, p. 415.

31 Arlettaz, Fernando, op. cit., p. 415. 
Artículo 20. Derecho a la Nacionalidad.

1. Toda persona tiene derecho a una nacionalidad.

2. Toda persona tiene derecho a la nacionalidad del Estado en cuyo territorio nació si no tiene derecho a otra.

3. A nadie se privará arbitrariamente de su nacionalidad ni del derecho a cambiar.

Igualmente, la mencionada Convención protege, en el artículo 11, la honra y la dignidad.

Aunque no existe disposición expresa en ningún ordenamiento jurídico nacional o internacional que aluda al derecho humano al gentilicio, la realidad es que múltiples ordenamientos constitucionales (nacionales e internacionales) aluden a ello directa o indirectamente. La misma Constitución Política de los Estados Unidos Mexicanos lo hace al mencionar el gentilicio mexicano (sobre todo en su versión en plural) en 288 ocasiones.

Ya se indicó, en el apartado correspondiente, que la esencia de los derechos humanos gira en torno al concepto de dignidad, y en el correspondiente al gentilicio, se advirtió el reflejo entre persona y su identidad nacional, manifestada a través del gentilicio. Morera expresa con enorme pulcritud la importancia del gentilicio: "Es decir, que esas palabras que llamamos gentilicios constituyen la raíz y el arranque del ansia que manifiestan los pueblos del mundo — sin distinción de tamaños - a la libertad y la independencia". ${ }^{32}$

Si bien es cierto que el mundo atraviesa por un proceso de integración global, al cual se le ha llamado globalización, la evidencia empírica muestra que las nacionalidades y los regionalismos siguen vigentes, de tal manera que exceptuando a la Unión Europea (entre los comunitarios europeos), que es la única región sin fronteras (parcialmente hablando), el resto del mundo las sigue teniendo; actualmente, la única mercancía que no tiene nacionalidad es el capital financiero; de ahí que ni las personas ni las mercancías están exentas del vínculo con su nación de origen.

Por ello, mientras el mundo no cambie, las personas deben ser protegidas en su espectro máximo, siguiendo los parámetros enunciados por la Constitución Política de los Estados Unidos Mexicanos, instrumento político que recoge lo mejor de la teoría sobre los derechos humanos, de tal manera que éstos son concebidos de una manera integral y aplicados de un modo amplificado, no restrictivo, en aras de alcanzar la mejor expresión de la dignidad humana.

\footnotetext{
32 Morera, Marcial, op. cit., p. 109.
} 


\section{Por qué el gentilicio debería ser reconocido como derecho humano}

La historia evidencia claramente la resistencia a los cambios; el statu quo, el conservadurismo, siempre han sido mayoría; sin embargo, la dinámica social, las revoluciones, la mutación, son la constante en el mundo natural y en el devenir humano.

Si el pensamiento estático hubiese imperado, los derechos humanos se hubiesen quedado en la primera generación, o, más aún, nunca se hubieran gestado, basándose en que el derecho natural ya los contiene, manteniendo la separación entre derecho positivo y aquél. Sin embargo, las nuevas ideas siempre se abren camino; ante el escepticismo de considerar derechos humanos que no se enfocaran en el individuo, sobrevivió y se impuso la idea de la existencia de los derechos humanos sociales y colectivos, y después el advenimiento de las últimas generaciones de derechos humanos, ${ }^{33}$ en las cuales se ha llegado al extremo de discutir si éstos deben estar reservados exclusivamente a los humanos. ${ }^{34}$

La opinión de Ortiz Millán demuestra claramente lo acertado de la crítica sustentada en falacias sobre la admisión o no de "nuevos" derechos:

...muchos piensan hoy en día que la atribución de los derechos de los animales es una cara más de la inflación que ha habido últimamente en el discurso de los derechos: se abusa del concepto y proliferan supuestos nada más porque la gente quiere proteger algo que considera valioso. Esto sólo debilita los derechos humanos... ${ }^{35}$

El mismo Ortiz Millán refuta lo anterior, al decir que los derechos de los animales (su reconocimiento) está moralmente justificado, al tratarse de una subespecie de los derechos morales, de los que los derechos humanos son otra subespecie, y que si están justificados, no existe ninguna razón para

33 Cfr. Guerrero Pino, Samir Hendrix e Hinestroza Cuesta, Lisneider, "El concepto de derechos humanos frente a los derechos de las minorías étnicas", Revista Prolegómenos Derechos y Valores, núm. 20, vol. 40, 2017, pp. 27-41.

34 Cfr. Ortiz Millán, Gustavo, “¿Tienen derechos los animales?”, en Larrañaga Monjaraz, Pablo et al. (coord.), Entre la libertad y la igualdad. Ensayos críticos sobre la obra de Rodolfo Vázquez, México, UNAM-IICQ-ITAM, 2017, t. I, disponible en: https://bi blio.juridicas.unam. $\mathrm{mx} / \mathrm{bj}$ /detalle-libro/4588-entre-la-libertad-y-la-igualdad-ensayoscriticos-sobre-la-obra-de-rodolfo-vazquez-tomo-i.

35 Ibidem, p. 385. 
negarles reconocimiento jurídico. ${ }^{36}$ Es oportuno resaltar: reconocimiento de los derechos animales. Lo mismo se empieza a discutir sobre "seres" no biológicos; el Estado Saudí Árabe, por ejemplo, le ha reconocido ciudadanía a una "robot". ${ }^{37}$

Es muy cierto que el "catálogo" de los derechos humanos es cada vez más extenso y que, coincido, lo ideal sería exclusivamente atender a los principios y que no hubiese necesidad de ampliar este listado que parece ser inagotable, pero en México la realidad práctica muestra que ante la falta de expresión de un derecho en la normatividad, se considera como si no existiera y se niega por supuesto la eficacia ante un caso específico; por otro lado, la realidad nos muestra que la gente requiere, como algo natural, puntos de referencia, elementos de identidad, sentido de pertenencia, abundar en los elementos psicológicos, antropológicos, históricos y sociológicos; esto supera con creces los parámetros de este trabajo, pero el discutirse en la arena política ${ }^{38}$ este tema es muestra efectiva de que la sociedad lo considera importante, ${ }^{39}$ y por tanto es menester que sea abordado en la teoría, y una vez demostrada la pertinencia de ser incluido explícitamente el derecho humano al gentilicio, que se legisle al respecto. ${ }^{40}$

\section{CASO PARADIGMÁTICO: CIUdAD DE MÉXICO}

\section{Mexicanos, gentilicio de un país}

La Ciudad de México, nos dice la historia (con mucho de leyenda), fue fundada el 20 de junio de 1325; el nombre originario de la ciudad fue el de Mexico-Tenochtitlan (Mexico, palabra grave, no esdrújula como en la actualidad, pronunciándose la "x" como "sh", no como la "j" actual), erigiéndose como la capital del pueblo mexica (o azteca). Dos siglos más tar-

\footnotetext{
36 Ibidem, p. 386.

37 Cfr. https://www.excelsior.com.mx/global/2017/10/26/1197432; https://www.bbc. com/mundo/noticias-41803576,y https://www.lanacion.com.ar/2076584-arabia-sauditaes-el-primer-pais-en-otorgarle-la-ciudadania-a-un-robot.

38 Cfr. http://www.milenio.com/estados/como-llamar-a-los-habitantes-de-la-ciudadde-mexico.

39 Cfr. http://www.academia.org.mx/espin/respuestas/item/gentilicio-de-ciudad-demexico.

40 Cfr.http://www.eluniversal.com.mx/articulo/metropoli/cdmx/2017/07/15/resistenciaal-nuevo-gentilicio.
} 
de, los españoles lograrían el sometimiento de los mexicas, conquistando plenamente su ciudad capital el 13 de agosto de 1521; durante tres siglos, el Imperio Español tuvo como colonia (o virreinato) a la mayor parte del actual Estado mexicano, bajo la denominación de Nueva España; la capital del territorio español más importante de ultramar lo sería la Ciudad de México, erigida sobre las ruinas de la antigua Mexico-Tenochtitlan. El 21 de septiembre de 1821 se lograría la independencia de México respecto de España, y desde entonces el nombre que se le da al nuevo país es el de México (teniendo diferentes denominaciones oficiales a lo largo del tiempo: Imperio Mexicano, República Mexicana; actualmente, Estados Unidos Mexicanos).

Como fácilmente puede apreciarse, la capital del pueblo mexica fue el origen del nombre que a la postre tendría todo el país.

Con el nombre del país, se dio paso al gentilicio que identifica a los nacidos en México: mexicanos.

Es importante tener presente este dato: la ciudad de México (es decir, Mexico-Tenochtitlan) existió 500 años antes que el país (y, en consecuencia, que el gentilicio mexicano, referido a los nacidos en el país México).

También es oportuno hacer referencia al eslogan publicitario con el cual, de manera falaz, el gobierno de la Ciudad de México "vendió" el que se haya aprobado la última reforma política de la Ciudad de México (modificación constitucional del 29 de enero de 2016) diciendo: "Hola Ciudad de México, adiós Distrito Federal". La realidad es que desde el 25 de octubre de 1993 el artículo 44 de la Constitución Política de los Estados Unidos Mexicanos indicaba:

Artículo 44. La Ciudad de México es el Distrito Federal, sede de los Poderes de la Unión y Capital de los Estados Unidos Mexicanos. Se compondrá del territorio que actualmente tiene y en el caso de que los poderes Federales se trasladen a otro lugar, se erigirá en el Estado del Valle de México con los límites y extensión que le asigne el Congreso General. ${ }^{41}$

En consecuencia, ni en el contexto histórico, como tampoco en el constitucional-legal, la Ciudad de México es un producto nuevo; esto es notoriamente una falacia producto de la ignorancia de la clase política.

41 Artículo que también adolecía de múltiples imprecisiones: la ciudad por definición se refiere a un ambiente urbano; el territorio que ocupa el Distrito Federal en un $56 \%$ es rural; por otro lado, geográficamente el Distrito Federal-Ciudad de México, No está asentado en un valle, sino en una cuenca. 
Como simple corolario, en un estado federal, la sede de los poderes de este nivel siempre será un distrito federal, llámesele como se le llame.

\section{2. ¿Mexica, mexicalino, mexiqueño o chilango?}

Pues bien, los nacidos en la Ciudad de México no tenemos un gentilicio; cuentan las personas de más de sesenta años que antes, en el interior del país, a la gente originaria de la capital se les decía "mexicanos", a sabiendas de que todos eran mexicanos, pero como distintivo de los nacidos en otras regiones; sin embargo, esto fue más bien un uso que no tuvo consecuencias oficiales, en cuanto hace a un gentilicio plenamente enfocado a la gente de México (la ciudad), ya que también, cuando se aludía a la capital, se le decía simplemente México, sin el complemento "Ciudad"; esta denominación sólo se daba en los discursos oficiales.

Desde los años ochenta del siglo pasado fue tema de debate entre la clase intelectual definir el gentilicio para los originarios de la Ciudad de México, debido especialmente a la generalización de chilango (palabra que inicialmente se refería a las personas migrantes que llegaban a la capital y la escogían como su lugar de residencia permanente), que con el tiempo se fue utilizando más y más en amplias regiones del país para referirse a los nacidos en la capital mexicana, siempre bajo un tamiz peyorativo. Es más que oportuno traer a colación el pensamiento de Moreno de Alba, filólogo que tuvo como objeto de estudio discernir si "chilango" podría ser el gentilicio de la gente de la Ciudad de México:

En la edición de la Ortografía académica (Espasa) del año 1999 aparecía, en el apéndice 2 ("Nombres de los países reconocidos por los organismos internacionales, con sus capitales y gentilicios"), chilango como gentilicio de "México, D. F., capital de México". Asimismo, en el DRAE de 2001, chilango tiene dos acepciones, ambas con la nota de "coloquial": 1) Natural de México (¿país, ciudad?); 2) Perteneciente o relativo a esta ciudad (aquí se aclara que es «ciudad») o a "este Distrito Federal, en México" (?). No deseo entrar, en esta nota, en el espinoso asunto de la etimología y origen de la voz chilango. Mejor debería decir: no puedo entrar, sobre todo porque no tengo la menor idea sobre la historia o procedencia de esa palabra. Las diversas hipótesis que sobre este tema he leído me parecen inaceptables. 
Lo que resulta indiscutible es que los registros escritos de la voz son muy recientes: fines del pasado siglo XX. ${ }^{42}$

Quiero detenerme en las marcas que lleva la voz en cada una de las dos obras citadas: por una parte, la marca de "gentilicio" (en la Ortografia) y, por otra, la de "coloquial" (en el DRAE). La gramática explica que el adjetivo gentilicio es aquel que denota la procedencia geográfica de las personas o su nacionalidad. Los gentilicios pertenecen a la clase de palabras llamadas "derivadas". Constan éstas de una raíz y de un sufijo (mexicano: mexic- [raíz] + -ano [sufijo]). En el caso de los gentilicios, en la raíz está la información del lugar; el concepto 'originario, procedente de' está en el sufijo (mexicano: "originario, procedente de México"). Los gentilicios, como cualquier otro tipo de palabras derivadas, se estudian en la morfología (una de las partes de la gramática). No toda palabra que designa procedencia u origen es un gentilicio. Para que un adjetivo pueda llamarse gentilicio se requiere que esté formado precisamente mediante una derivación: mexicano procede de México; madrileño de Madrid; aguascalentense, de Aguascalientes. Hay en español muchas palabras que, sin ser derivadas, designan procedencia u origen. No conviene llamarlas gentilicios, pues al no ser derivadas, no constan de raíz y sufijo, como se exige que estén formados los gentilicios.

En México y en otras partes de América se emplea en ocasiones el adjetivo, evidentemente despectivo, gachupín, para designar, en general, a los españoles. ¿Quiere decir que gachupín es un gentilicio? De ninguna manera, pues no se trata de una voz derivada. Es probable que, hace siglos, a cierto tipo de españoles establecidos en América, por determinadas razones, se les llamara gachupines (o algo semejante). Poco a poco esa designación fue extendiéndose a otros españoles no radicados en América, y el vocablo acabó por ser, en alguna medida, y dentro de determinados dialectos, contextos y registros, sinónimo de español. El despectivo gachupín, por tanto, designa hoy procedencia u origen, pero no es un gentilicio, pues no es fragmentable en raíz y sufijo, como todo gentilicio. Lo mismo sucede con otros adjetivos, no necesariamente despectivos, como jarocho ("originario del puerto de Veracruz") o tapatio ("de Guadalajara"). Ni jarocho ni tapatio tienen, en su estructura, una raíz que remita a la ciudad de Veracruz o de Guadalajara. No son, por tanto, gentilicios, aunque signifiquen procedencia $\mathrm{u}$ origen. A este tipo de voces pertenece chilango (sin ser gentilicio, refiere a un origen o procedencia). Resulta por tanto inconveniente su inclusión en la lista de gentilicios que aparece en la Ortografia.

42 Moreno de Alba, José J., Minucias del lenguaje, Fondo de Cultura Económica, México. 
Ahora bien, en el DRAE, chilango tiene la marca de coloq. (coloquial). En el mismo Diccionario se nos aclara que coloquial es lo "propio de una conversación informal y distendida". Creo que, por ejemplo, jarocho o tapatio podrían merecer en efecto esa marca (coloquial), aunque bien pueden no llevarla. En la nota biográfica de un personaje importante, tal vez no se anotaría "destacado político jarocho", sino veracruzano; pero cualquiera diría "me gusta el buen humor de los jarochos". La marca que no podría llevar ni tapatío ni jarocho es la de despectivo. Por sí mismas estas voces no resultan ofensivas. En el otro extremo estaría el vocablo $g a-$ chupín. En efecto, la sola voz y no necesariamente el contexto manifiesta cierta idea de menosprecio.

En mi opinión, chilango está más cerca de lo despectivo (como gachupín) que de lo meramente coloquial, como podría ser jarocho. En el CREA (Corpus de referencia del español actual), hay sólo ocho apariciones de chilango. La más antigua es apenas de 1987, y procede de Cristóbal Nonato, de Carlos Fuentes. En todos estos textos chilango tiene, en mayor o menor medida, un evidente valor despectivo. Resulta particularmente revelador un texto procedente de un diario de Yucatán en el que se discute precisamente el sentido que el autor quiso dar a esta voz. El título del artículo es "Chilangos y chilanguismo". Copio sólo un breve fragmento:

"Tal altanería, combinada con la idea de que fuera de México todo es Cuautitlán, constituye la infraestructura psicológica del chilanguismo. Agréguese el centralismo irreductible del gobierno y la abyección de los millones que ignoran que «mandatario» significa «mandadero» y no «mandamás», y tendremos la explicación de esa imaginaria superioridad que convierte a algunos capitalinos en chilangos al momento en que salen a la provincia. Huelga decir que mientras más civilizado sea un capitalino, más ajeno es a esa barbarie. Diría el gran Ortega que no es más que una manifestación local de la rebelión de las masas, cuyos entes llegan «al interior del país» a enjuiciarnos sin más criterio que su ignorancia, ni más autoridad que la de venir de la capital. Del odio suscitado por el centralismo en general y por el chilango en particular salió la igualmente odiosa consigna de «Haz patria: mata un chilango»".

Queda claro que chilango no es exactamente una voz coloquial, sino francamente despectiva, por decir lo menos. Con alguna frecuencia se emplea para denigrar o injuriar. Si nos atenemos a la explicación transcrita (del diario yucateco), resulta que chilango no sólo no es gentilicio sino que tampoco designa a los naturales de la ciudad de México, ni siquiera coloquialmente. Designa sólo a algunos capitalinos que parecen 
hacerse merecedores de calificativos tales como centralistas, abyectos, bárbaros, ignorantes, odiosos... No todos los capitalinos son chilangos. Los chilangos son una clase particular de capitalinos. No dudo de que hoy también, así sea esporádicamente, se emplee el adjetivo chilango sin estas claras connotaciones injuriosas y que, al paso del tiempo, pueda llegar a ser un simple sinónimo de capitalino. Mientras ello sucede, convendría corregir cuidadosamente la definición del vocablo en los diccionarios.

Aun cuando se pensó que en la Constitución de la Ciudad de México podría definirse oficialmente cuál debería ser el gentilicio en cuestión, finalmente esto no prosperó; aunque el uso de "chilango" cada vez es más generalizado y es aceptado por mucha gente, la realidad es que también para un alto porcentaje de la gente originaria de la Ciudad de México le suena desagradable, más como un apodo, y no pueden reconocerse en un adjetivo que tiene una evidente connotación despectiva.

Hasta antes de la modificación constitucional de 2016 en que convivían como nombres oficiales Distrito Federal y Ciudad de México, se utilizó, sobre todo en medios intelectuales, el gentilicio de defeño, pero nunca fue asumido como propio por la población en general, de tal manera que quedó como una propuesta sin éxito, y debido a que "oficialmente" ${ }^{43}$ se eliminó al Distrito Federal.

La Real Academia de la Lengua, en su diccionario, refiere que el gentilicio que debe adoptarse para nuestro caso es el de mexiqueño: ${ }^{44}$

mexiqueño, ña

1. adj. Natural de México, capital de la república mexicana. U. t. c. s.

2. adj. Perteneciente o relativo a México o a los mexiqueños.

A pesar de que la máxima autoridad institucional del idioma español indica que "mexiqueño" es el gentilicio de los naturales de México (la capital), es un adjetivo que no es usado por la población, de tal modo que no puede aceptarse como válido este "gentilicio". Moreno de Alba se pronunció al respecto de la manera siguiente:

43 La Constitución Política de los Estados Unidos Mexicanos vigente al 17 de julio de 2017 sigue teniendo SIETE referencias a Distrito Federal en diferentes artículos (sin contar las relativas a los artículos transitorios, lo cual sería perfectamente entendible).

44 Disponible en: http://dle.rae.es/?id=P900Kvu. 
En la vigésima segunda edición del DRAE (2001) hay un artículo dedicado a la voz mexiqueño, que cuenta con dos acepciones ("natural de México" y "perteneciente o relativo a esta ciudad, capital de la República Mexicana"). También el reciente Diccionario panhispánico de dudas (2005), en el artículo mexicano, -na, cree necesario aclarar lo siguiente: "No debe confundirse este gentilicio [mexicano] con mexiquense, que es como se denomina a la persona oriunda del Estado de México, uno de los treinta y uno que conforman los Estados Unidos Mexicanos, ni con mexiqueño, que es el gentilicio de los naturales de la capital del país". ${ }^{45}$

Sin duda el gentilicio mexiqueño está bien formado, pues a la raíz mexic-se añade el sufijo -eño que, entre otros derivados, también forma numerosos gentilicios (acapulqueño, toluqueño, caribeño...). El problema que yo veo no está, entonces, en una morfología defectuosa. No me convence empero el vocablo por la sencilla razón de que, en mi opinión, nadie lo usa. Nunca he oído en boca de un mexicano o de un hispanohablante el adjetivo mexiqueño. Tampoco lo he visto escrito, excepción hecha de los diccionarios mencionados. ¿A qué se debe, entonces, su presencia en las dos obras citada? Tengo entendido que hace algunos años la Academia Mexicana de la Lengua, al percatarse de la inexistencia de un gentilicio referido a la ciudad de México, lo propuso a la Real Academia Española y ésta lo incorporó en su diccionario del año 2001. La propuesta, en sí misma, no es mala. Sin embargo, si pasados cinco años, la voz no parece haber tenido éxito, resultaría mejor suprimirla. ${ }^{46}$

Recientemente, León Portilla, quizá la máxima autoridad en temas de historia prehispánica de México, propuso como opción al gentilicio para la Ciudad de México el de mexicalino; en síntesis, estas fueron sus razones:

\section{Mexicano capitalino}

Las comisiones de Consultas y Lexicografía de la Academia Mexicana de la Lengua estudian el caso y consideran que los vocablos "chilango", "defeño" y "mexiqueño" tienen que ser descartados por distintas razones, plenamente sustentadas. Con base en la filiación histórica de la ciudad con la nación, se sugiere, tentativamente, que el término "mexicano" que designa genéricamente a las personas con la nacionalidad correspondiente podría ser también un gentilicio que remitiera los moradores de la Ciudad de México así como a todo lo relacionado con ella. Para despejar la ambi-

\footnotetext{
45 Moreno de Alba, op. cit.

46 Idem.
} 
güedad, se propone añadir el epíteto "capitalino" a "mexicano" de manera sistemática, o a discreción, cuando sea necesario. ${ }^{47}$

Mexicapitalino

El binomio "mexicano capitalino", si bien es preciso, al mantener separados sus componentes no tienen el valor sintéticamente emblemático de un apelativo con carácter genérico. Una forma más entrañablemente gentilicia se podría derivar, sin embargo, de esta locución nominal dando mexicapitalino, fusión de dos términos en una entidad léxica. ${ }^{48}$

Mexicalino

El gentilicio mexicapitalino, además de ser algo extenso, mantiene la palabra-concepto "capitalino" de manera transparente en el término. El hecho de que la ciudad-Estado sea también la capital del país no debe reflejarse de manera tan flagrante en el gentilicio, por lo que proponemos una fusión aún más sintética de los componentes que diluya una locución que podría ser superlativa. La palabra gentilicia resultante sería mexicalino, vocablo obtenido a partir de mexicapitalino mediante la exclusión de dos sílabas. ${ }^{49}$

En términos semánticos, el gentilicio náhuatl mexica correspondiente a la etnia indígena que dio su nombre a la ciudad, en tiempos prehispánicos, permanece intacto en la palabra. En cuanto a lino, alude de manera intencionalmente difusa al adjetivo "(capita)lino". Por otra parte, se percibe, en el palimpsesto de la palabra, el radical cal de calli "casa" en náhuatl o la sílaba ca de "capital". ${ }^{50}$

En términos fonéticos, la secuencia sonora es eufónica, agradable. Contiene cuatro de las cinco vocales del alfabeto español. Se pronuncia [mejicalino]con una fricativa glotal sorda para la " $x$ ". Se puede pronunciar también a la manera náhuatl: [meshicalino], con una fricativa palatal sorda. Es cromática, por el color de sus cuatro vocales, y además aterciopelada, líquida (por la "l" y la "i"). ${ }^{51}$

La proximidad fonética de Mexicali, ciudad norteña cuyo gentilicio oficial es, como ya lo expresamos, "mexicalense" (y de manera más coloquial pero más usual: "cachanilla") podría ser un obstáculo, ya que el sufijo no puede tener en español un valor gentilicio. Sin embargo, con el uso, el tér-

47 León-Portilla, Miguel, “CDMX: un gentilicio para una ciudad-Estado", Proceso, 9 de marzo de 2016, disponible en: http://www.proceso.com.mx/432894/cdmx-gentiliciouna-ciudad.

48 Idem.

49 Idem.

50 Idem.

51 Idem. 
mino mexicalino se volvería arbitrario, borrando asimismo, con el tiempo, las huellas sonoras de una semejanza parásita. ${ }^{52}$

La composición del gentilicio mexicalino que propongo para los habitantes de la Ciudad de México, puede parecer algo artificial. Sin embargo, si consideramos que tanto Mexicali: Méxi(co) y Cali(fornia), como la ciudad del otro lado de la frontera, Calexico: Cal(ifornia) y (M)éxico, son montajes silábico-léxicos, el neologismo gentilicio mexicalino podría ser viable. $^{53}$

Por último, el ex comisionado para la reforma política de la Ciudad de México, Porfirio Muñoz Ledo, propuso como gentilicio para la gente de la capital el de mexica, lo cual expreso en entrevista en los términos siguientes:

"Mexicas", la propuesta de Muñoz Ledo para el gentilicio de la CDMX. ${ }^{54}$

El político mexicano recordó que cuando el territorio capitalino se llamaba Distrito Federal, "nos llamábamos defeños", gentilicio con el que durante años nos reconocieron no sólo a nivel nacional e incluso internacional. Sin embargo, ante la creación de la Constitución y el cambio del nombre de la capital del país, "se perdió identidad". Es por ello que, durante el foro organizado por el Instituto de la Juventud de la Ciudad de México (Injuve), planteó "rendirle homenaje a nuestros ancestros, a esa tribu que llegó a fundar esta ciudad, y que fueron los mexicas".

A su vez, negó la posibilidad de otorgar el gentilicio de "chilango", propuesta, entre otros, del jefe de gobierno de la Ciudad de México, Miguel Ángel Mancera, pues no lo consideró "muy conveniente". "Llamarnos mexicas sería una forma de que los habitantes de esta capital nos sintamos orgullosos de nuestras raíces históricas", indicó. ${ }^{55}$

\section{CONCLUSIONES}

El concepto de "derechos humanos" es dinámico, y seguramente seguirá afinándose y perfeccionando con el paso del tiempo; posiblemente el aspecto que se vaya ampliando con mayor notoriedad sea el relativo a su contenido: los derechos humanos casuísticamente.

\footnotetext{
52 Idem.

53 Idem

54 Disponible en: http://www.elfinanciero.com.mx/nacional/propone-munoz-ledo-que -sea-mexicas-como-gentilicio-en-la-cdmx.html.

55 Idem.
} 
Consideramos que el gentilicio es un caso específico de derecho humano que no había sido considerado por la literatura especializada, posiblemente por su relación con el de nacionalidad, pero evidentemente, con lo explicado en este trabajo, queda claro que el gentilicio responde a demandas distintas que la nacionalidad, y muestra un contenido social, cultural, moral y jurídico distinto al de la nacionalidad.

Probablemente el gentilicio sea una de las manifestaciones más íntimas de la personalidad, por lo cual merece una tutela jurídica.

En el caso de las personas originarias de México (la ciudad capital), se ha menoscabado su derecho a un gentilicio en beneficio de los nacionales de los Estados Unidos Mexicanos; pero la historia muestra que fue la ciudad la que compartió su denominación con el país, lo cual muestra un evidente perjuicio hacía los naturales de la Ciudad de México.

Si bien se han ensayado varias propuestas para elegir el gentilicio de la gente de México, se necesita una fuerte campaña de difusión para involucrar a la población en este tópico que es de suma importancia.

La propuesta de mexicalino, por los argumentos expuestos, parece ser la mejor.

\section{BIBLIOGRAFÍA}

AlEMÁn OCAMPO, Carlos, No confundamos apodos colectivos con gentilicios, disponible en: http://www.elcastellano.org/artic/gentilicios.htm.

ARLETTAZ, Fernando, "La nacionalidad en el derecho internacional americano", Anuario Mexicano de Derecho Internacional, vol. XV, 2015.

CARPIZO, Jorge, "Los derechos humanos: naturaleza, denominación y características", Cuestiones Constitucionales, Revista Mexicana de Derecho Constitucional, núm. 25, julio-diciembre de 2011.

Corte InTERnacional de Justicia (CIJ), Affaire Nottebohm (Liechtenstein v. Guatemala), Deuxième phase: arrêt, Recueil, 1955.

Cuervo Álvarez, Benedicto, Textos literarios. Gramática, sintaxis y ortografia (1/3), disponible en: http://www.mailxmail.com/curso-textosliterarios-gramatica-sintaxis-ortografia-1-3/gramatica-gentilicios.

Guerrero Pino, Samir Hendrix e Hinestroza Cuesta, Lisneider, "El concepto de derechos humanos frente a los derechos de las minorías étnicas", Revista Prolegómenos Derechos y Valores, núm. 20, vol. 40, 2017. 
LEÓN-PorTILlA, Miguel, "CDMX: un gentilicio para una ciudad-Estado", Proceso, 9 de marzo de 2016, disponible en: http://www.proceso.com. $m x / 432894 / c d m x$-gentilicio-una-ciudad.

MARTÍNEZ BulLÉ-GOYRI, Víctor M., "Reflexiones sobre la dignidad humana en la actualidad", Boletín Mexicano de Derecho Comparado, nueva serie, año XLVI, núm. 136, enero-abril de 2013.

Moreno de AlBA, José J., Minucias del lenguaje, México, Fondo de Cultura Económica, disponible en: https://www.fondodeculturaeconomica. com/obra/suma/r2/buscar.asp? word2=chilango.

MORERA, Marcial, "Gentilicios y seudogentilicios: mostración vs. descripción”, Revista de Lexicografía, XVIII, 2012.

Niboyet, J. P., Principios de derecho internacional privado, México, Ed. Nacional, 1965.

ORTIZ Millán, Gustavo, “ ¿Tienen derechos los animales?”, en LARRAÑAGA MonjaraZ, Pablo et al. (coord.), Entre la libertad y la igualdad. Ensayos críticos sobre la obra de Rodolfo Vázquez, México, UNAMIICQ-ITAM, t. I, 2017, disponible en: https://biblio.juridicas.unam.mx/ bjv/detalle-libro/4588-entre-la-libertad-y-la-igualdad-ensayos-criti cos-sobre-la-obra-de-rodolfo-vazquez-tomo-i.

Pereznieto, Leonel, Derecho internacional privado, México, Harla, 1994.

PÉREZ, Elisa, Derecho internacional privado, Madrid, Facultad de Derecho de la Universidad Nacional de Educación a Distancia, 1990.

Fecha de recepción: 25 de julio de 2017.

Fecha de aceptación: 08 de octubre de 2018. 